\title{
Information and Announcements
}

\section{Science Academies' Fifty-Sixth Refresher Course in Experimental Physics}

\author{
11 to 16 February 2014
}

Sponsored by Indian Academy of Sciences, Bangalore, Indian National Science Academy, New Delhi

The National Academy of Sciences, India, Allahabad

In collaboration with Department of Physics, Panjab University, Chandigarh

A Refresher Course in Experimental Physics will be held at the Department of Physics, Panjab University, Chandigarh from 11 to 26 February 2014 for the benefit of faculty involved in teaching undergraduate and postgraduate courses. The Course aims to familiarize the teachers with a set of new experiments developed as a low cost kit by the Indian Academy of Sciences to cater to the BSc and MSc levels. All the experiments verify physical laws and principles and yield reasonably accurate results. The Refresher Course is jointly sponsored by the Indian Academy of Sciences, Bangalore; Indian National Science Academy, New Delhi; The National Academy of Sciences India, Allahabad.

Professor R. Srinivasan, a distinguished physicist, who has designed these experiments for the benefit of physics teachers and students in Indian Universities will be the Course Director. The Course comprising lectures, discussions and laboratory sessions will help participants hone their skills in experimental physics and enable them to introduce the experiments in their respective curricula. UGC has approved two-week Refresher Courses of good standing for promotion, vide notification - F3-1/2009 dated 30 June 2010.

Applications are invited from teachers with experience in teaching undergraduate and postgraduate courses in Engineering and Physics. Motivated students of III BSc and MSc Physics courses with keen interest in Experimental Physics may also apply. The participation of faculty and students from universities and colleges from north India is preferred. The number of seats will be about 25 . Selected participants will be provided local hospitality during the Course in addition to course material. Outstation participants will be given three-tier $A / c$ train fare.

Interested applicants can download the application form from Panjab University website http://physics.puchd.ac.in/ events/rcep2014. The printed application form filled and signed by the applicant should be sent by Post to the Course Coordinator. The form must also be signed and stamped by the Head of the applicant's Institution. Recommendation letter from a teacher is essential for student applicants.

Applications will also be accepted if sent with the following details: name, age, gender, educational qualification, designation, address for communication, telephone/mobile numbers and e-mail id. Applications may be sent to:Professor Devinder Mehta, Course Coordinator, 56th Refresher Course in Experimental Physics, Department of Physics, Panjab University, Chandigarh 160 014, Email: dmehta@pu.ac.in, Tel: +91 9815973101

Last date for the receipt of applications: 31 December 2013; Selected participants will be informed by: 11 January 2014 